\title{
Helping Students Learn in EMI Courses Using Reciprocal Teaching: A Case Study of a Taiwan University
}

\author{
I-Chia Chou ${ }^{1}$ \\ ${ }^{1}$ Center for Teacher Education, Wenzao Ursuline University of Languages, Taiwan \\ Correspondence: I-Chia Chou, Associate Professor, Center for Teacher Education, Wenzao Ursuline University \\ of Languages, Taiwan.
}

Received: August 1, 2016

Accepted: August 30, $2016 \quad$ Online Published: September 4, 2016

doi:10.20849/aes.v1i2.57

URL: http://dx.doi.org/10.20849/aes.v1i2.57

\begin{abstract}
Offering English-medium-instruction (EMI) courses in universities and colleges has gradually become a national policy in Taiwan. However, many students struggle in EMI courses. One possible reason is that Taiwanese students do not have sufficient English competence to understand academic text and academic lectures in English. Reciprocal teaching (RT) has been considered an effective way to increase students' reading comprehension in many elementary and junior-high school language classrooms. Yet, few studies have been done for tertiary-level students. Thus, this small-scale pilot study was conducted to examine whether there was an effect of reciprocal teaching on students' academic performance. A class of 62 students enrolling in Educational Psychology was taught first in a traditional lecturing style (about 2 months) and later in RT (about 2 months). Data was collected at four time periods (2 in-class quizzes and 2 achievement tests). Results of one-way repeated ANOVA showed that there was a significant difference on students' test score before and after the intervention. This suggests that the RT technique may help Taiwanese students comprehend academic text and further help them learn in EMI courses.
\end{abstract}

Keywords: English-medium instruction (EMI), reciprocal teaching, EFL, higher education

\section{Introduction}

\subsection{Introduce the Problem}

In response to the trend of globalization, the Ministry of Education (MOE) in Taiwan has started to encourage universities and colleges to expand the percentage of English Medium Instruction (EMI) lectures to allow students to gain both specialized knowledge and enhanced English ability. In other words, students can learn the main subjects of their academic field while practicing their English (Kim, Son \& Sohn, 2009). While this policy seems to be a promising plan, the effectiveness of current EMI lectures in Taiwanese higher education has been questioned. There are several important factors related to the successful implementation of EMI classes, including suitable learning materials, appropriately trained instructions, a perceived need for English as a medium of instruction, a threshold level of learner proficiency in the medium language, and a supportive language environment in the larger societal context (Gu, 2004; $\mathrm{Hu}, 2002)$.

My personal experience with EMI has not been satisfying. I have been teaching an EMI course, Educational Psychology, in a teacher-training program for more than five years. Every year, my students complain about not being able to understand the course content. "Use Chinese, please!" is a common suggestion I get from the end-of-course feedback of my students. Because students have difficulties understanding the content of the textbook or the lecture in EMI, their performance in quizzes or examinations is usually poor. These difficulties are not limited to students with low English proficiency. Even though English proficiency plays a crucial role in students' academic achievements in EMI classes, students with high language proficiency can also experience the same difficulties. This is because academic English is a different genre from daily-used English. Many students may perform well in regular English courses but still suffer greatly in English-only academic courses. Researchers (Li \& Munby, 1996; Nambiar, 2005) make it clear that there is a distinction between English for everyday purposes and for academic purposes. Moreover, the ability to read and understand academic text is highly correlated with academic success (Doolittle, et al., 2006; Hart and Speece, 1998; Lewis, 2000; Nakatani, 2005). If students can understand the assigned English reading texts, it will further help them understand English-only lectures. 


\subsection{Explore Importance of the Problem}

Even though many Taiwanese students have learned English for more than nine years before they enter college, most undergraduate students do not acquire good reading strategies to help them comprehend reading texts, unfortunately. Given that the explicit teaching of reading comprehension strategies has been demonstrated to be effective in enhancing learning and performance (Bulter \& Winne, 1995; Hatties, Briggs \& Purdie, 1996), the question arises, "What comprehension strategies can be effectively employed in the college classroom?" One answer to this question is reciprocal teaching (RT). Therefore, I conducted this action research to evaluate the effect of RT on my students' academic performance.

\subsection{Describe Relevant Scholarship}

Many studies have been conducted to test RT's effectiveness (e.g., Brown, 1997; Hart \& Speece, 1998; Rosenshine \& Meister, 1994; Takala, 2007). Hart and Speece (1998), for example, conducted an experimental study to investigate the effects of RT on 50 postsecondary students at risk for academic failure. Results from their first and secondary analyses showed that the RT group performed significantly better than the comparison group on reading comprehension and strategy acquisition. Rahmani and Sada (n.d.) investigated students' reading comprehension on narrative text through the RT technique. By using classroom action research involving 32 sixth graders, they found that students' reading comprehension on narrative text improved after the implementation of the RT technique, especially in finding the main idea and moral value. Takala (2007) incorporated RT in mainstream and special classes of fourth and sixth graders. The results showed that students' reading comprehension in both types of classes improved after the implementation of RT. In Allen's (2003) study, the RT instruction was taught to the students for two weeks prior to the reading activities. The study found positive changes in the students' abilities to generate questions, answer questions, and summarize information. Finally, Hashey and Connors (2003) in their action-research paper found significant improvements in students' confidence and success, in their recognizing and use of strategies, and in their enjoyment of literature after RT was used in their classroom. This study concluded by agreeing with most of the students that RT helps them understand the book more and facilitates their reading comprehension. Although results differ according to the kinds of measures used to evaluate instructional effectiveness, using RT has been found to increase students' reading comprehension consistently.

Many RT studies have also been done in Taiwan. Lin (2005), for example, explored effects of RT on the reading comprehension of four fourth-grade elementary students in a resource classroom. The results showed that the method of RT could improve reading comprehension of the tested students. The students, moreover, enjoyed dialogue in this teaching mode. Ho and Lee (2003) investigated the effects of RT on three fourth-grade elementary at-risk readers. They found that students had better understanding of certain comprehension questions that were challenging to them before she used the RT method. In addition, students' overall Chinese reading comprehension improved. Additionally, Lin (2004) used the RT method on three junior-high school students with reading difficulties. She compared students' understanding of narrative and exploratory texts. The results were consistent with previous studies showing that students' reading comprehension of both types of writings increased.

According to Slater and Horstman (2002), RT helps students prevent cognitive failure during reading. Palincsar and Brown (1984) mentioned that RT is an instructional procedure in which students learn to improve their reading comprehension through active participation in their reading process by using comprehension-fostering and comprehension-monitoring strategies. These strategies are predicting, clarifying, questioning, and summarizing. In general, the prediction phase of reciprocal teaching helps readers combine their own background knowledge with what they have understood from the text. This phase helps readers recall their prior knowledge or text-related schema. In the questioning phase, readers ask themselves questions and monitor and assess their understanding of the text. For example, readers can ask about the main idea or some supporting ideas. "Clarifying phrase" refers to the identification and clarification of unclear, difficult, or unfamiliar aspects of a text. Readers recognize comprehension failure and use strategies to remedy the comprehension breakdown. In the summarizing phase, the important information, themes, and ideas in the text are integrated into a clear and concise statement that communicates the total meaning of the text (Ghorbani, Gangeraj \& Alavi, 2013).

Some educators and teachers modify their practice of RT in accordance with their teaching contexts. Hacker and Tenent (2002), for example, reported how elementary-school teachers modified the practice of RT while keeping three essential elements of RT - strategy use, dialogue, and scaffolded instruction. Some teachers in this report added whole-class discussion due to the low quality of group dialogue. In addition, two strategies, questioning and summarization, were the most observed, but clarifying was often omitted. Prediction was reported by the 
teachers as an awkward strategy when the students read expository texts. In these cases, the students would often pass over prediction and go directly to questioning. Finally, some teachers had their students write their questions, answers, and summaries. By adding writing as an addition to RT, teachers were able to help students focus on deeper rather than superficial understanding of the text. In the article by Doolittle et al. (2006), each author delineated how he or she used RT in his or her academic classroom in different academic fields, including psychology, history, and literacy, as well as provided some suggestions to put theory into practice. For example, one author, Doolittle, used RT on training students to read scholarly articles. He suggested making explicit connections between the new section of the text and students' previously learned knowledge (p.109). Another author, Hicks, helped students summarize a historical article by asking some basic questions. Moreover, he provided the source analysis chart to help students move through the RT process (p.110). Finally, Young reported using RT to help students put theory into practice. Specifically, RT was viewed as a process via which students generated meaning from a specific text and made their own connections with the world.

\subsection{Significance of the Study and Research Question}

Even though many studies have been conducted and proved that RT is an effective method to improve students' reading comprehension, most of the studies targeted elementary or high- school students. In addition, studies in Taiwan have concerned the reading outcomes in students' first language, Chinese, rather than in a foreign language such as English. Finally, most of the studies have been conducted mainly in language classrooms. The method of RT has rarely been implemented when teaching academic courses in an English-medium environment at the higher education level. The current article focuses on the implementation of RT in a higher education setting. The research question addressed to guide the study was:

Is there a significant difference in students' academic performance before and after the implementation of the RT technique?

\section{Method}

\subsection{Site, Participants, and Design}

This study was conducted at a language university in southern Taiwan. The intervention, the RT approach, was implemented in a three-credit academic course, Educational Psychology. This course is required for all students from the TESOL (Teaching English to Speakers of Other Languages) department. Due to the policies of the department, all courses offered by the department must be taught in English. In addition, this course is offered in the second semester each academic year. In other words, students enrolling in this course have taken at least two English-medium instruction (EMI) courses in the first semester.

Sixty-two (10 male and 52 female) students enrolled in this course participated in this study. The mean age of the students was 19.5 years. There were two sections of this course. Before the midterm (week 9), a traditional lecture style was the main teaching method. After the midterm, starting from week 10, the RT approach was implemented. The traditional method was implemented for eight weeks, the same as that of the RT intervention. A total of six chapters were taught in one semester.

The RT approach used in this study was modified based on suggestions from previous studies due to time constraints. The procedure of RT implementation was as follows:

(1) Questioning: Before starting a new chapter, the instructor intentionally divided one chapter into several sections. For each section, the instructor posed some pre-reading questions (usually 6-10) on the one class-discussion board. Students had to find the answers from the textbook and then write them down before they came into the class. The preview questions included the identification of information and ideas that are central and important enough to warrant further consideration (Doolittle et al., 2006, p.107). These questions served as a summary guideline to lead students into the new chapter.

(2) Summarizing: When students came in the class, they were first asked to share their answers with their group members (4-6 people). When one student shared, other students added or commented on the answers as needed. As mentioned before, the preview questions were designed as a summary guideline; therefore, this sharing process was viewed as a summarizing process. After the group discussion, the instructor summarized the reading section to make sure that student understanding was accurate.

(3) Clarifying: After the whole-class summary, the instructor moved on to identify sections of the text where clarification was needed. The students were free to ask questions to clarify unclear concepts. During the clarifying process, the instructor sometimes would show related videos to make some difficult concepts understandable. 
(4) Integrating: Once students understood the reading section, the instructor would integrate the current section of text with the preceding sections or with students' previous knowledge or daily experiences.

RT was used again for the following section of the chapter, starting with the instructor posting questions as the first step of the procedure.

\subsection{Data Collection and Analysis}

Students' academic performance was measured using their two-time quiz scores and their midterm and final exam scores. Even though the chapters for the midterm and final exams were different, the difficulty of the theories was similar based on the instructor's past experiences.

A one-way repeated measures analysis of variance was conducted to compare scores among students with achievement test at four time periods with time 1 and time 2 prior to the intervention and time 3 and time 4 after the intervention. The two-time attitude questionnaires were computed using the paired t-test.

\section{Results}

This case study investigated the effects of RT instruction on a class of 62 students. A one-way repeated ANOVA was implemented for determining significant differences between the students' academic performance before and after the RT intervention. Two test scores were collected before and after the intervention. Table 1 shows the means and standard deviations of test scores at the four time periods. Students' test scores at time 1 and time 2 were 45 out of 100 points on average. After the intervention of RT, the test scores seemed to increase to 47 at time 3 and further to 52 at time 4 .

Table 1. Descriptive statistics

\begin{tabular}{lll}
\hline & Mean & Std. Deviation \\
\hline Time1 & 45.45 & 14.31 \\
Time2 & 44.55 & 15.66 \\
Time3 & 46.79 & 17.10 \\
Time4 & 52.19 & 17.49 \\
\hline
\end{tabular}

A one-way repeated measures analysis of variance was conducted to compare scores among students with achievement test at four time periods with time 1 and time 2 prior to intervention and time 3 and time 4 after intervention. Mauchly's test (Table 2 ) indicated that the assumption of sphericity had been violated, $x^{2}(5)=$ $16.22, \mathrm{p}=.006$.

Table 2. Mauchly's Test of sphericity

$$
\text { Epsilon(a) }
$$

\begin{tabular}{|c|c|c|c|c|c|c|c|}
\hline $\begin{array}{l}\text { Within Subjects } \\
\text { Effect }\end{array}$ & Mauchly's W & $\begin{array}{l}\text { Approx. } \\
\text { Chi-Square }\end{array}$ & $\mathrm{df}$ & Sig. & $\begin{array}{l}\text { Greenhouse- } \\
\text { Geisser }\end{array}$ & Huynh-Feldt & Lower-bound \\
\hline time & .76 & 16.22 & 5 & .006 & .848 & .888 & .333 \\
\hline
\end{tabular}

According to Field (2005), two ways can be used to compensate for this assumption violation. The first one is to use multivariate statistics. As seen in Table 3, all four multivariate tests suggested rejection of the null hypothesis $(\mathrm{p}<.05)$. This indicated that there was a change in test scores across the four different time periods. The second approach was to correct degrees of freedom by using Greenhouse-Gressier estimates of sphericity $(\varepsilon=.85)$ (Table 4). The results showed that there was a significant effect on students' test scores during different periods, $\mathrm{F}(2.5,155.18)=4.67, \mathrm{p}=.006$. These results suggested that students' learning achievement improved significantly from the beginning to the end of the semester. 
Table 3. Multivariate tests

\begin{tabular}{|c|c|c|c|c|c|c|c|}
\hline Effect & & Value & $\mathrm{F}$ & $\begin{array}{l}\text { Hypothesis } \\
\text { df }\end{array}$ & Error df & Sig. & $\begin{array}{l}\text { Partial Eta } \\
\text { Squared }\end{array}$ \\
\hline \multirow[t]{4}{*}{ Time } & Pillai's Trace & .18 & $\begin{array}{l}4.41 \quad(a) \\
\text { (Note 1) }\end{array}$ & 3 & 59 & .007 & .18 \\
\hline & Wilks' Lambda & .82 & 4.41(a) & 3 & 59 & .007 & .18 \\
\hline & Hotelling's Trace & .22 & 4.41(a) & 3 & 59 & .007 & .18 \\
\hline & $\begin{array}{l}\text { Roy's Largest } \\
\text { Root }\end{array}$ & .22 & 4.41(a) & 3 & 59 & .007 & .18 \\
\hline
\end{tabular}

Table 4. Tests of within-subjects effects

\begin{tabular}{llrrrrrr}
\hline \multirow{2}{*}{ Source } & & $\begin{array}{c}\text { Type III } \\
\text { Sum of } \\
\text { Squares }\end{array}$ & df & Mean Square & F & Sig. & Partial Eta Squared \\
\hline TIME & Sphericity Assumed & 2181.34 & 3 & 727.11 & 4.662 & .004 & .071 \\
& Greenhouse-Geisser & 2181.34 & 2.54 & 857.45 & 4.662 & .006 & .071 \\
& Huynh-Feldt & 2181.34 & 2.66 & 818.82 & 4.662 & .005 & .071 \\
& Lower-bound & 2181.34 & 1 & 2181.34 & 4.662 & .035 & .071 \\
Error(TIME) & Sphericity Assumed & 28544.42 & 183 & 155.98 & & & \\
& Greenhouse-Geisser & 28544.42 & 155.18 & 183.94 & & & \\
& Huynh-Feldt & 28544.42 & 162.50 & 175.65 & & & \\
& Lower-bound & 28544.42 & 61 & 467.94 & & & \\
\hline
\end{tabular}

Bonferroni pairwise comparisons then were used to compare each pair of time points and whether the differences between them were significant. Table 5 showed that there were significant differences between test 1 and test 4 $(\mathrm{p}=.004)$ and between test 2 and test $4(\mathrm{p}=.045)$. The results suggest that students' achievement scores significantly increase over time.

Table 5. Pairwise comparisons (Note 2)

\begin{tabular}{|c|c|c|c|c|c|c|}
\hline \multirow[t]{2}{*}{ (I) TIME } & \multirow[t]{2}{*}{ (J) TIME } & \multirow[t]{2}{*}{$\begin{array}{r}\text { Mean Difference } \\
\text { (I-J) }\end{array}$} & \multirow[t]{2}{*}{ Std. Error } & \multirow[t]{2}{*}{ Sig.(a) } & \multicolumn{2}{|c|}{$\begin{array}{l}\text { 95\% Confidence Interval for } \\
\text { Difference(a) }\end{array}$} \\
\hline & & & & & Lower Bound & Upper Bound \\
\hline \multirow[t]{3}{*}{1} & 2 & .90 & 2.21 & 1.00 & -5.12 & 6.92 \\
\hline & 3 & -1.34 & 1.93 & 1.00 & -6.61 & 3.93 \\
\hline & 4 & $-6.74(*)$ & 1.86 & .004 & -11.81 & -1.67 \\
\hline \multirow[t]{3}{*}{2} & 1 & -.90 & 2.21 & 1.00 & -6.92 & 5.12 \\
\hline & 3 & -2.24 & 2.22 & 1.00 & -8.30 & 3.82 \\
\hline & 4 & $-7.65\left(^{*}\right)$ & 2.77 & .045 & -15.19 & -.11 \\
\hline \multirow[t]{3}{*}{3} & 1 & 1.34 & 1.93 & 1.00 & -3.93 & 6.61 \\
\hline & 2 & 2.24 & 2.22 & 1.00 & -3.82 & 8.30 \\
\hline & 4 & -5.40 & 2.36 & .15 & -11.83 & 1.02 \\
\hline \multirow[t]{3}{*}{4} & 1 & $6.74(*)$ & 1.86 & .004 & 1.67 & 11.81 \\
\hline & 2 & $7.65(*)$ & 2.77 & .045 & .11 & 15.19 \\
\hline & 3 & 5.40 & 2.36 & .15 & -1.02 & 11.83 \\
\hline
\end{tabular}




\section{Discussion, Conclusion and Limitations}

This study investigated the effects of RT intervention on the academic learning outcome of EFL university students. Although the size of the data is small, the results seem to be promising. The results show that after the students learned through RT instruction, their academic performance improved. Even though the students' scores at time 3 did not significantly differ from the scores at time 1 or time 2 , their final scores at time 4 were significantly higher than those taken before the RT instruction. The finding indicates that students' academic performance can be effectively promoted through RT instruction, which is in accordance with the findings of previous studies conducted among young learners (Takala, 2007) and in language classrooms (Ho \& Lee, 2003; Lin, 2005).

Prior research has shown that RT can be suitable as a remediation technique to help learners with reading problems (Marston et al., 1995; Schmidt, Rozendal \& Greenman, 2002; Slater \& Horstman, 2002). Although the purpose of this study is also to solve students' English reading problem, the main innovation of this teacher-inquiry study is that the RT has been carried out as part of normal teaching for undergraduate students in the academic field. Through the four components of RT, students are provided more chances to be exposed to the text content than through traditional lecture-type instruction. The questioning requires the students to preview the reading text. During the summarizing and clarifying processes, students can check and confirm their understanding through discussion with one another and through the instructor's lecture. The students then apply what they have learned to real-life examples or compare new knowledge with their prior knowledge in the integration process. As a result, the students generally revisit the reading texts at least three times before they move on to the next section.

In this modified version of RT, the instructor is the initiator and the facilitator. Because of time constraints, the students have not been trained to develop these reading strategies and become autonomous learners. More research is needed on students' academic achievement if they are equipped with these reading strategies. Moreover, long-term implementation is strongly recommended. The present study was conducted only within one semester. As Hashey and Connors (2003) have suggested, students need time to practice these strategies to apply them to their learning. Therefore, in order for students to learn all the strategies and be able to apply those strategies in other EMI courses, they need to be taught over a period longer than four months. Finally, only one class of students participated in this study. A comparison group is highly recommended for further investigation.

\section{References}

Allen, S. (2003). An analytic comparison of three models of reading strategy instruction. IRAL: International Review of Applied Linguistics in Language Teaching, 41(4), 319-339. http://dx.doi.org/10.1515/iral.2003.015

Brown, A. (1997). Transforming schools into communities of thinking and learning about serious matters. American Psychologist, 4, 399-413. http://dx.doi.org/10.1037/0003-066X.52.4.399

Bulter, D., \& Winne, P. (1995). Feedback and self-regulated learning: A theoretical synthesis. Review of Educational Research, 65, 245-281. http://dx.doi.org/10.3102/00346543065003245

Doolittle, P. E., Hicks, D., Triplett, C. F., Nichols, W. D., \& Young, C. A. (2006). Reciprocal teaching for reading comprehension in higher education: A strategy for fostering the deeper understanding of texts. International Journal of Teaching and Learning in Higher Education, 17(2), 106-118.

Ghorbani, M. R., Gangeraj, A. A., \& Alavi, S. Z. (2013). Reciprocal teaching of comprehension strategies improved EFL learners' writing ability. Current Issues in Education, 16(1), 1-11.

Gu, Y. (2004). Bilingualism as policy: What can we learn from the Hong Kong experience? Paper presented at international conference on foreign language teaching methodology in China, Shanhai, China.

Hacker, D. J., \& Tenent, A. (2002). Implementing reciprocal teaching in the classroom: Overcoming obstacles and making modifications. Journal of Educational Psychology, 94(4), 699-718. http://dx.doi.org/10.1037/0022-0663.90.4.670

Hart, E. R., \& Speece, D. L. (1998). Reciprocal teaching goes to college: Effects for postsecondary students at risk for academic failure. Journal of Educational Psychology, 90, 670-681. http://dx.doi.org/10.1037/0022-0663.90.4.670

Hashey, J. M., \& Connors, D. J. (2003). Learn from our journey: Reciprocal teaching action research. Reading Teacher, 57(3), 224-233. Retrieved from http://www.jstor.org/stable/20205347

Hatties, J., Briggs, J., \& Purdie, N. (1996). Effects of learning skills interventions on student learning: A 
meta-analysis. Review of Educational Research, 66, 99-136. http://dx.doi.org/10.3102/00346543066002099

Ho, C. H., \& Lee, P. C. (2003). The effectiveness of reciprocal teaching on students with reading comprehension difficulties. Unpublished thesis.

Hu, G. (2002). The craze for English-medium education in China: Driving forces and looming consequences. English Today, 25(4), 47-54. http://dx.doi.org/10.1017/S0266078409990472

Kim, A., Son, Y. D., \& Sohn, S. Y. (2009). Conjoint analysis of enhanced English medium instruction for college $\begin{array}{lllll}\text { students. } & \text { Expert } & \text { Systems }\end{array}$ http://dx.doi.org/http://dx.doi.org/10.1016/j.eswa.2009.01.080

Lewis, J. (2000). Academic literacy: Reading and strategies. NY: Houghton.

Li, S., \& Munby, H. (1996). Metacognitive strategies in second language academic reading: A qualitative $\begin{array}{lllll}\text { investigation. } & \text { English for } & \text { Specific } & \text { Purposes, } & 15(3),\end{array}$ http://dx.doi.org/10.1016/0889-4906(96)00004-X

Lin, P. H. (2004). The effects of reciprocal teaching on reading comprehension of junior high school students with learning disabilities. Retrieved August $27^{\text {th }}$, 2016 from http://handle.ncl.edu.tw/11296/ndltd/86216338933634944164

Lin, P. H. (2005). Effects of reciprocal teaching on reading comprehension improvements for students at resource classroom of elementary school. Unpublished thesis.

Nakatani, Y. (2005). The effects of awareness raising training on oral communicative strategy use. Modern Language Journal, 89, 76-91. http://dx.doi.org/10.1111/j.0026-7902.2005.00266.x

Nambiar, R. (2005). Why don't they read the way they should? Retrieved October 15th 2006 from ERIC Document Reproduction Service No. ED 490379.

Palincsar, A. S., \& Brown, A. L. (1984). Reciprocal teaching of comprehension-fostering and comprehension-monitoring activities. Cognition and Instruction, 1, 117-175. http://dx.doi.org/10.1207/s1532690xci0102_1

Rahmani, E. F., \& Sada, C. (n.d.). Improving students' reading comprehension on narrative text through reciprocal teaching technique. Retrieved November 4th, 2013 from http://jurnal.untan.ac.id/index.php/jpdpb/article/view/2206

Rosenshine, B., \& Meister, C. (1994). Reciprocal teaching: A review of the research. Review of Educational Research, 64(4), 479-530. http://dx.doi.org/10.3102/00346543064004479

Slater, W. H., \&Horstman, F. R. (2002). Teaching reading and writing to struggling middle school and high school students: The case for reciprocal teaching. Preventing School Failure, 46(4), 163. http://dx.doi.org/10.1080/10459880209604416

Takala, M. (2007). The effects of reciprocal teaching on reading comprehension in mainstream and special (SLI) education. Scandinavian Journal of Education Research, 50(5), 559-576. http://dx.doi.org/10.1080/00313830600953824

\section{Notes}

Note 1. a. Exact statistic

b. Design: Intercept Within Subjects Design: Time

Note 2. Based on estimated marginal means

* The mean difference is significant at the .05 level.

a Adjustment for multiple comparisons: Bonferroni

\section{Copyrights}

Copyright for this article is retained by the author(s), with first publication rights granted to the journal.

This is an open-access article distributed under the terms and conditions of the Creative Commons Attribution license (http://creativecommons.org/licenses/by/4.0/). 